\title{
Establishing operant conflict tests for the translational study of anxiety in mice
}

\author{
Oberrauch, Sara ; Sigrist, Hannes ; Sautter, Eva ; Gerster, Samuel ; Bach, Dominik R ; Pryce,
} Christopher R

\begin{abstract}
RATIONALE In conflict-based anxiety tests, rodents decide between actions with simultaneous rewarding and aversive outcomes. In humans, computerised operant conflict tests have identified response choice, latency, and vigour as distinct behavioural components. Animal operant conflict tests for measurement of these components would facilitate translational study. OBJECTIVES In C57BL/6 mice, two operant conflict tests for measurement of response choice, latency, and vigour were established, and effects of chlordiazepoxide (CDZ) thereon investigated. METHODS Mice were moderately diet-restricted to increase sucrose reward salience. A 1-lever test required responding under medium-effort reward/threat conditions of variable ratio 2-10 resulting in sucrose at $\mathrm{p}=0.7$ and footshock at $\mathrm{p}=0.3$. A 2-lever test mandated a choice between low-effort reward/threat with a fixed-ratio (FR) 2 lever yielding sucrose at $\mathrm{p}$ $=0.7$ and footshock at $\mathrm{p}=0.3$ versus high-effort reward/no threat with a FR 20 lever yielding sucrose at $\mathrm{p}=1$. RESULTS In the 1-lever test, CDZ (7.5 or $15 \mathrm{mg} / \mathrm{kg}$ i.p.) reduced post-trial pause (response latency) following either sucrose or footshock and reduced inter-response interval (increased response vigour) after footshock. In the 2-lever test, mice favoured the FR2 lever and particularly at post-reward trials. CDZ increased choice of FR2 and FR20 responding after footshock, reduced response latency overall, and increased response vigour at the FR2 lever and after footshock specifically. CONCLUSIONS Mouse operant conflict tests, especially 2-lever choice, allow for the translational study of distinct anxiety components. CDZ influences each component by ameliorating the impact of both previous punishment and potential future punishment.
\end{abstract}

DOI: https://doi.org/10.1007/s00213-019-05315-y

Posted at the Zurich Open Repository and Archive, University of Zurich

ZORA URL: https://doi.org/10.5167/uzh-175356

Journal Article

Accepted Version

Originally published at:

Oberrauch, Sara; Sigrist, Hannes; Sautter, Eva; Gerster, Samuel; Bach, Dominik R; Pryce, Christopher R (2019). Establishing operant conflict tests for the translational study of anxiety in mice. Psychopharmacology, 236(8):2527-2541.

DOI: https://doi.org/10.1007/s00213-019-05315-y 


\section{Establishing operant conflict tests for the translational study of anxiety in mice}

Sara Oberrauch ${ }^{1}$, Hannes Sigrist ${ }^{1}$, Eva Sautter ${ }^{2}$, Samuel Gerster ${ }^{3}$, Dominik R. Bach ${ }^{3 *}$, Christopher R. Pryce ${ }^{1^{*}}$

1 Preclinical Laboratory for Translational Research into Affective Disorders, Department of Psychiatry, Psychotherapy and Psychosomatics, Psychiatric Hospital, University of Zurich, August Forel-Strasse 7, CH-8008 Zurich, Switzerland

2 TSE Systems GmbH, Siemensstrasse 21, D-61352 Bad Homburg, Germany

3 Computational Psychiatry Research, Department of Psychiatry, Psychotherapy and Psychosomatics, Psychiatric Hospital, University of Zurich, Lenggstrasse 31, CH-8032 Zurich, Switzerland

*Authors contributed to the work equally

Running title: Translational mouse anxiety tests

Corresponding author: Christopher Pryce, PLaTRAD, Department of Psychiatry, Psychotherapy and Psychosomatics, Psychiatric Hospital, University of Zurich, August Forel-Strasse 7, CH8008 Zürich, Switzerland. E-mail: christopher.pryce@bli.uzh.ch

Funding and disclosures: This research was funded by the Swiss National Science Foundation (grant 31003A-160147 to CRP). ES is an employee of TSE Systems, Germany. All remaining authors declare no competing interests. 


\begin{abstract}
Rationale: In conflict-based anxiety tests, rodents decide between actions with simultaneous rewarding and aversive outcomes. In humans, computerized operant conflict tests have identified response choice, latency and vigour as distinct behavioural components. Animal operant conflict tests for measurement of these components would facilitate translational study. Objectives: In C57BL/6 mice, two operant conflict tests for measurement of response choice, latency, and vigour were established, and effects of chlordiazepoxide (CDZ) thereon investigated. Methods: Mice were moderately diet-restricted to increase sucrose reward salience. A 1-lever test required responding under medium-effort reward/threat conditions of variable ratio 2-10 resulting in sucrose at $p=0.7$ and footshock at $p=0.3$. A 2-lever test mandated a choice between low-effort reward/threat with a fixed ratio (FR) 2 lever yielding sucrose at $p=0.7$ and footshock at $p=0.3$ versus high-effort reward/no threat with a FR 20 lever yielding sucrose at $p=1$. Results: In the 1-lever test, CDZ (7.5 or $15 \mathrm{mg} / \mathrm{kg}$ i.p.) reduced post-trial pause (response latency) following either sucrose or footshock and reduced inter-response interval (increased response vigour) after footshock. In the 2-lever test, mice favoured the FR2 lever and particularly at post-reward trials. CDZ increased choice of FR2 and FR20 responding after footshock, reduced response latency overall, and increased response vigour at the FR2 lever and after footshock specifically. Conclusions: Mouse operant conflict tests, especially 2-lever choice, allow for the translational study of distinct anxiety components. CDZ influences each component by ameliorating the impact of both previous punishment and potential future punishment.
\end{abstract}

Key words: anxiety; reward-aversion conflict; translational test; mouse; operant choice; response latency; response vigour; anxiolytic 


\section{INTRODUCTION}

Daily functioning often involves deciding between competing goals: for example, an individual wants to obtain food but at the same time wants to avoid physical threat. These goals are determined by internal needs such as exploration, hunger, socio-sexual interest, safety, and the external stimuli of innate and conditioned rewards and punishers. The conflict between competing goals invokes behaviours that are often collectively termed 'anxiety-like' and that are sensitive to anxiolytic drugs (Griebel and Holmes 2013). Animal behaviour tests that induce goal conflict constitute the primary preclinical models of human anxiety (Bach and Dayan 2017; Calhoon and Tye 2015; Gray et al., 1981; Gray and McNaughton 2000; Ito and Lee 2016; Kirlic et al., 2017; Tovote et al., 2015). Ethological tests in rodents are based on spontaneous approach-avoidance conflict behaviour in an unfamiliar environment; for example, in the elevated plus maze open arms can be explored at the cost of exposure whilst closed arms provide relative safety at the cost of lost exploration (Dawson and Tricklebank 1995). In the Vogel conflict test (Vogel et al., 1971), both the reward that elicits approach and the punishment that elicits avoidance are more salient than in maze tests: subjects are waterdeprived and thirsty, and can lick water from a spout but a certain number of licks (e.g. every $20^{\text {th }}$ ) results in an electric footshock. A high amount of approach behaviour, as induced by benzodiazepines, results in more water and more footshocks and is interpreted as reflecting low anxiety. Operant conflict tests have also been developed. In the Geller-Seifter test, subjects are food-deprived and trained to lever press for food. In the test session, using a variable-interval schedule, signalled phases of high-effort food reinforcement alternate with signalled phases of low-effort food reinforcement or footshock punishment; relatively high operant responding in the second phase type is interpreted as low anxiety (File et al., 2004; Varty et al., 2005). While the above tests allow animals to either respond or not respond, they do not present a choice between alternative actions. A small number of operant tests based on such choice discrimination have also been developed. For example, food-deprived rats were presented with a concurrent choice between two operant levers, responding on one lever yielded low food/no footshock and on the other yielded high food/footshock (Amemori et al., 2015; Shimp et al., 2015; Simon and Setlow 2012). Such anxiety tests that are based on discrimination between alternative choices add an important dimension that is not available in other tests; for example, a fooddeprived rodent can still choose to feed even if it is too anxious to risk punishment (Jean-Richard-DitBressel et al., 2018).

Recently, informed by the approach-avoidance conflict that underlies rodent tests, computerized tests for the study of anxiety in humans have been developed and applied. One such test involves the subject moving out of a safe home base to collect reward tokens at the risk of being caught by a "virtual predator" and losing the collected tokens; distance from the home base and overall predator activity determine the probability of being caught (Bach et al., 2014). As in rodent conflict 
tests, this test is sensitive to anxiolytic drugs (Bach et al., 2018; Korn et al., 2017) and ventral hippocampus lesions (Bach et al., 2014), as well as amygdala lesions (Korn et al., 2017). In a refined version of the test that allowed for separate analysis of several components of subjects' actions, we found that the choice of whether to approach a reward, the latency to initiate a response (ie. behavioural inhibition), and the speed of the response sequence (i.e. behavioural vigour), were each sensitive to the probability and degree of punishment (Bach 2015). In addition to this, an exploratory analysis of magnetoencephalography data suggested that choice and latency may be associated with neural oscillations in different hippocampal regions (Khemka et al., 2017), raising the question of whether the different components are under distinct neural control.

To support the summary concept of studying 'anxiety-like' rodent behaviour in conflict tests, a large rat study with $\mathrm{N}>700$ indicated that several readouts from different conflict tests (black/white box, elevated zero-maze, novel cage activity test) loaded onto one common factor (Lopez-Aumatell et al., 2008). However, when analysing more detailed read-outs in such ethological tests it transpires that, even within one test, different variables load onto different meaningful factors (Rodgers et al., 1997). For example, a study based on the elevated plus maze in mice identified six interpretable factors for the various behavioural readouts, although typically these are grouped together as 'anxiety-like' behaviour. Thus, an 'anxiety factor' was characterised by open and closed arm time, a 'risk assessment factor' had loadings of stretch-attend posture and sniffing behaviour, an 'exploration factor' was characterised jointly by stretch-attend posture and head dips, and a 'decision factor' had loadings of time spent in the centre and closed (but not open) arm time/entries (Rodgers and Johnson 1995). These findings indicate that there are distinct components to behaviour in anxiety tests, and that these components can differ in their importance across individuals. Such heterogeneity over individuals is relevant to the study of adaptive anxiety and clinical anxiety: patients with anxiety disorders exhibit specific behavioural components according to the type of disorder. For example, generalised anxiety disorder is characterised by inhibition of behaviour in the face of every-day tasks that can ultimately be performed, while arachnophobia is defined by complete avoidance of and absence of voluntary approach to spiders.

This evidence, together with the possibility that neural control for different behavioural components may differ (Bach and Dayan 2017; Khemka et al., 2017), motivates measuring these components separately. However, ethological tests such as the elevated plus maze, in which the goals of individual actions are difficult to establish, may not be optimal for this. Rather, operant conflict tests may provide more opportunity to study a menu of specific actions with possibly distinct underlying regulation and consequences/functions. Whilst this approach can be applied in rodent operant anxiety tests, it has been relatively unexplored to date, with only a few but nonetheless encouraging exceptions, e.g. (Evenden et al., 2009; Shimp et al., 2015). 
In the present study we established two operant conflict tests in mice, the designs of which were informed by (1) the human evidence that response choice, latency and vigour constitute important components in the translational study of anxiety, and (2) the advantage of providing subjects with a choice between high reward/high aversion or low reward/low aversion. In the first test, food-deprived mice were presented with a single operant lever, responding at which resulted in either food reward or footshock aversion at set probabilities; response latency and response rate following reward or punishment were measured. In the second test, food-deprived mice were presented with two operant levers predictably associated with high-effort food reward/no footshock versus low-effort food reward/footshock; response choice, latency and rate following reward or punishment in the preceding trial were measured. Many components of anxiety-like behaviour, even though possibly controlled independently, are sensitive to benzodiazepines. Here we investigated the effects of chlordiazepoxide on each of the different measures.

\section{METHODS AND MATERIALS}

Animals and maintenance

The study was conducted with adult male C57BL/6J mice bred in-house. Mice were weaned at age 4 weeks and kept in littermate pairs throughout the experiment. Cages measured $33 \times 21 \times 14 \mathrm{~cm}$ and contained woodchips, a sleep igloo and tissue bedding. They were placed in an individually-ventilated system with temperature at $21-23^{\circ} \mathrm{C}$ and humidity at $50-60 \%$. The animal room had a reversed $12: 12$ h light-dark cycle (lights off 07:00-19:00 h). Water was available continuously. Complete-pellet diet (Provimi, Kliba Ltd, Kaiseraugst, Switzerland) was available ad libitum until the onset of operant training at age 12-14 weeks (see below). To prepare mice for the experiment they were first handled for $5 \mathrm{~min}$ on each of 3 days, and were then transported to and remained in the experimental room for $3 \mathrm{~h}$ on the following 2 days to adjust them to these procedures. The experimental room was dimly lit and maintained at $21-23^{\circ} \mathrm{C}$ and $40 \%$ humidity. The study was conducted under a permit (149/2015) for animal experimentation issued by the Zurich Veterinary Office, Switzerland. The principles of laboratory animal care were followed, including that the number of mice studied was the minimum necessary to achieve the study aims and all unnecessary stress was avoided.

\section{Food restriction protocol}

In mice aged 10-12 weeks, individual body weight and weight of food eaten per pair of cage mates were measured on each of 5 days and used to calculate mean $100 \%$ baseline values per mouse. During the following week mice were reduced to $90-95 \%$ baseline body weight by food restriction and were maintained within this range throughout the experiments. Mice then received some sucrose pellets in 
the home cage on 2 days to familiarize them with the operant reward, and we then commenced with operant training.

\section{Apparatus}

The purpose-built apparatus used for both tests comprised an operant chamber (26 (L) x 20 (W) $\times 25$ $(\mathrm{H}) \mathrm{cm}$ ), with walls and ceiling constructed from panels of grey or transparent Plexiglas (Fig. 1; TSE Systems, Bad Homburg, Germany). The floor was a grid comprising stainless steel rods $(\varnothing=4 \mathrm{~mm}$, inter-rod distance $=10 \mathrm{~mm}$ ) through which electric current could be delivered. The chamber was equipped with two retractable levers, one each side of the rear wall, referred to as the operant levers (OLs). It was also equipped with two additional retractable levers, referred to as the feeder levers (FLs); these were located one on each of the side walls and at the front of the chamber, directly next to a feeder port for pellet-delivery (Fig. 1). Each feeder port comprised a circular recess behind a vertical Plexiglas barrier, into which single sucrose pellets (14 mg, Dustless Precision Pellets, BioServ) were delivered from an automated pellet dispenser. The vertical Plexiglas barrier could be raised and lowered to control access to the feeder port. When the barrier was raised, the mouse extending and withdrawing its head into and from the port to collect the pellet was detected via infra-red beam. Constant low-level white noise was generated to override any external noise in the experimental room. The entire operant chamber was placed within an attenuation chamber. Two such units were used, each connected to a control unit and a PC running IntelliMaze software (TSE Systems) with control and data processing functions. The apparatus was purpose-designed to facilitate efficient training and to physically separate reward delivery from operant responding; the latter served to increase the likelihood that the mouse would be at a distance from the operant levers when each trial was initiated, thereby facilitating decision making prior to operant responding. The presence of the vertical barrier in front of the feeder port prevented development of alternation between lever press and feeder visit behaviours, which can otherwise be common in rodent operant tests. The FLs were used specifically to facilitate acquisition of operant lever pressing for sucrose reinforcement i.e. training, and were not used in the conflict tests per se. All mice attained criterion at all stages of training and completed operant testing.

(FIGURE 1 ABOUT HERE)

\section{Operant training}

On each training and test day mice were transported to the experimental room and body weight was measured. Mice were fed in the afternoon, several hours after training or testing. 
Familiarization. Cage mates were placed together in the chamber with all levers retracted for 20 min. Ten sucrose pellets were available in each open feeder port. Therefore, the stress of introduction to a new environment was not accompanied by the stress of social separation. The following day mice were placed singly into the chamber and the same amount of pellets were available. Mice were required to eat 20 pellets to proceed to feeder port training.

For each of the following training stages mice were placed in the chamber alone, a house light was on throughout the session, the session started with a "free" pellet available in one port, and in each reinforcement trial a $1 \mathrm{~s}$ tone signalled that the criterion for reinforcement had been attained. Feeder port training. Each training session was conducted with 1 of the 2 feeder ports (Fig. 2). After retrieving the first free pellet, the transparent vertical barrier closed and the inter-trial interval (ITI) of $45 \mathrm{~s}$ started. After each ITI, the next sucrose pellet was delivered into the feeder port, the vertical barrier opened, the mouse retrieved the pellet and then the barrier closed again. Criterion to proceed to the next stage was $\geq 30$ pellets eaten within $30 \mathrm{~min}$ and at least one session at each feeder port. Mice required 2-5 sessions to complete feeder port training.

Operant lever training: stage 1. We anticipated that acquiring the association between operant lever pressing to activate barrier opening of and pellet delivery into the remote feeder port would otherwise require multiple sessions, and therefore introduced an intermediate training stage. This involved mice pressing the feeder lever (FL) which was located directly adjacent to the feeder port (Fig. 1A, 2). Responding at the FL elicited its retraction, opening of the vertical barrier of the adjacent feeder port and pellet delivery. Only one FL was extended per session, and mice were initially trained on the left $\mathrm{FL}$ and then the right FL.

Operant lever training: stage 2. The next stage involved extending the left operant lever (OL), pressing of which triggered its retraction, extension of the left $\mathrm{FL}$, which was then pressed to trigger barrier opening and pellet delivery (Fig. 2). Mice were then trained on the right OL-FL-pellet delivery sequence. Each OL was set at fixed ratio 1 (FR1) and the time out before the next trial onset was $5 \mathrm{~s}$. The criterion to proceed from one stage to the next was $\geq 30$ pellets eaten within $30 \mathrm{~min}$. Mice required 6-12 sessions to complete operant lever training. Feeder levers were only used for this stage of operant training and were not used in subsequent training or tests. Whilst we did not have the impression that use of the OL-FL-feeder port training sequence had any unwanted effects on test behaviour, in future studies it would probably be sufficient for efficient training to proceed from FL-feeder port training directly to OL-feeder port training. After completion of basic operant lever training mice proceeded to a final training stage specific to either the one- or two-lever conflict test.

\section{Operant tests}

One-lever operant conflict test 
Eighteen mice (nine pairs) were studied in the one-lever conflict test (Fig. 1B). Only one OL and the corresponding feeder port were used in this test and mice were allocated equally to the left- or rightside for training and testing. Mice were trained further at FR1 OL-feeder port opening and pellet delivery, without footshock, and were required to complete 3 consecutive sessions of earning $\geq 35$ pellets within 30 min (3-7 sessions required) (Fig. 2). They were then tested for chlordiazepoxide effects on FR1 responding for reward (see below). Mice were then trained on the OL using variable ratio 2-10 (VR2-10 i.e. minimum 2, maximum 10, mean 6 ) for feeder port opening and pellet delivery (Fig. 2); training criterion was $\geq 35$ trials completed within $30 \mathrm{~min}$ in one session, and mice required 13 sessions to attain criterion and thereafter proceeded to the one-lever conflict test. The test consisted of three consecutive phases: Reward phase 1 (R1), maximum of 10 trials or 10 min with OL at VR2-10 leading with probability $p=1$ to 1 pellet; Conflict phase (reward/punishment, R/P), maximum of 20 trials or 20 min with OL at VR2-10 leading with $p=0.7$ to 1 pellet and $p=0.3$ to footshock at $0.1 \mathrm{~mA}$ for $1 \mathrm{~s}$; Reward phase 2 (R2), identical parameters to R1 (Fig. 2). Session parameters were $10+20+10$ trials or 40 min maximum, therefore. Measures of interest were test duration and, for each phase separately, as relevant: Post-reward pause (PRP), interval between end of time-out after sucrose pellet and the first OL response of the subsequent trial. Post-punishment pause (PPP), interval between end of time-out after footshock and the first OL response of the subsequent trial. The PRP and PPP are measures of what we refer to as response latency. Post-reward lever-press interval (PR-LPI), mean interval between consecutive lever presses at OL on trial after sucrose pellet. Post-punishment LPI (PPLPI), mean interval between consecutive lever presses at $\mathrm{OL}$ on trial after footshock. The PR-LPI and PP-LPI are inverse measures of what we refer to as response vigour. The effects of the benzodiazepine chlordiazepoxide on these one-lever conflict test measures were investigated using a latin-square design. The rationale for the three test phases was that the reward-only phases would maintain motivation to lever press across sessions and that the $20 \mathrm{R}+\mathrm{P}$ trials would be sufficient to detect anxiolytic or anxiogenic pharmacological effects.

\section{(FIGURE 2 ABOUT HERE)}

Two-lever operant conflict test

Eighteen mice (nine pairs), a separate cohort to that studied in the one-lever test, were studied in the two-lever conflict test (Fig. 1C). For training, mice were presented simultaneously with both OLs running on a fixed ratio (FR) schedule, with one OL at FR2 leading with $p=1$ to 1 pellet (FR2-R) and the other OL at FR20 leading with $p=1$ to 1 pellet (FR20-R) (Fig. 2). After 2 responses had been made at FR2-R, both levers were retracted, and the pellet was delivered. After 2 responses had been made at FR20-R, FR2-R was retracted and the mouse had $40 \mathrm{~s}$ within which to make the remaining 18 lever presses. This limited duration for FR20-R trials was based on pilot observations and was used to provide 
mice with sufficient time to complete the required lever presses but also to avoid long periods of within-trial no responding. Failed trials were those in which the FR was not completed within $40 \mathrm{~s}$ and there were few such trials; when one did occur, after a $5 \mathrm{~s}$ time out the OLs were extended again for the next trial. We assumed that mice would learn a preference for the less effortful FR2-R. To test whether this was the case, training sessions of 50 trials were conducted where trials 1-20 were used to assess OL preference, the left-right positions of FR2-R and FR20-R were exchanged at trial 21 and trials 21-30 were used for reversal learning, and then trials 31-50 were used to assess OL preference again. Training success was defined as at least 1 session where FR2-R was selected on $>70 \%$ of trials 1 $20+31-50$. Mice required 20-25 sessions to attain this $>70 \%$ criterion. Thereafter, mice were allocated equally to FR2-R being located on the left- or right-side, and the spatial position of the two OLs remained the same for each mouse throughout testing. A baseline session comprising 40 trials with FR2-R and FR20-R was conducted. In the final test condition, FR2-R became FR2-R/P, with 2 responses leading with $p=0.7$ to 1 pellet and with $p=0.3$ to $1 \mathrm{~s}$ footshock; FR20-R continued to lead with $p=1$ to 1 pellet (i.e never to footshock) (Fig. 2). One session was carried out each with footshock amplitude at 0.1 and $0.15 \mathrm{~mA}$, and for subsequent drug testing each mouse was allocated to the lowest amplitude at which it exhibited the shift to equable responding at FR20-R and FR2-R/P. Session parameters were 40 trials or 40 min maximum. Measures of interest were: test duration; number of trials completed on each OL and number of failed trials; post-reward and post-punishment choice of OL; post-reward pause (PRP, vis. response latency) with differentiation according to which OL was selected on this next trial; post-punishment pause (PPP, vis. response latency) with differentiation according to which $\mathrm{OL}$ was selected on this next trial; mean lever press interval (LPI) on FR2-R/P and FR20-R, with differentiation according to whether the mouse was rewarded (PR-LPI) or punished (PP-LPI) on the previous trial (vis. response vigour).

\section{Chlordiazepoxide and experimental design}

The benzodiazepine anxiolytic chlordiazepoxide hydrochloride (CDZ, Research Biochemicals Incorporated) was used to investigate the predictive validity of the one- and two-lever operant conflict tests. CDZ was dissolved in sterile physiological saline as vehicle (VEH) and stored at $4^{\circ} \mathrm{C}$ for 5 days maximum. Mice were injected i.p. at $30 \mathrm{~min}$ before testing with $\mathrm{VEH}, 7.5$ or $15 \mathrm{mg} / \mathrm{kg}$ (calculated as base) in a volume of $5 \mathrm{ml} / \mathrm{kg}$. These two doses were selected because they were expected to cover a range within which at least one dose would exert an anxiolytic effect in the absence of effects on general activity, satiety or nociception. In the one-lever test experiment, to test for CDZ effects on reward responding in the absence of conflict, mice were allocated to one dose group and FR1 rewardonly tests were conducted on 3 consecutive days followed on the next day with a fourth test without drug. The half-life of CDZ in mouse is about $6 \mathrm{~h}$ in blood and brain such that levels are $5-10 \%$ of the 
peak level after $24 \mathrm{~h}$ (Coutinho et al., 1969). For one-lever conflict testing each mouse received each CDZ dose according to a latin square design, with at least 2 days separating successive tests. In the two-lever experiment, each mouse received each CDZ dose according to a latin square design, with at least 2 days separating successive tests. On one of these 2 days a reward-only session (i.e. FR2-R and FR20-R) was conducted to ensure that mice returned to adaptive, low-cost reward-directed behaviour under these threat-free conditions. CDZ effects on reward-only responding were then assessed using the FR20-R only. Finally in these mice, after 4 days without drug or operant testing a hot plate test was conducted to test for CDZ effects on nociception (it was not possible to use conflict-test footshock reactivity as a measure of nociception because the operant apparatus was not equipped for activity measurement). The mouse was placed inside a chamber on a hot plate set to $50^{\circ} \mathrm{C}$; the latency to the first sign of nociception, defined as paw licking, paw flinching or jumping, was measured followed immediately by removal from the hot plate and return to the home cage (Azzinnari et al., 2014). Mice were tested at the same CDZ dose that they received in their last conflict test session.

Data analysis

For both tests, mean values for post-reward and post-punishment pauses (latency) and OL press intervals (vigour) were calculated for each mouse and session; for the two-lever test, OL choice was also analysed. Statistical analysis was performed using linear mixed models (LMM) in SPSS (version 20, SPSS Inc., Chicago IL, USA). In the one-lever test, R+P trials were analysed in a Dose (VEH, 7.5, $15 \mathrm{mg} / \mathrm{kg}$ ) $x$ Trial-type (post-reward, post-punishment) model. In the two-lever test, when assessing footshock amplitude effects, behaviours occurring post-reward $(0,0.1,0.15 \mathrm{~mA}$ tests) or post-punishment (0.1, $0.15 \mathrm{~mA}$ tests) were analysed in a Footshock amplitude $\times$ OL on subsequent trial (FR2-R/P, FR20-R) model. To assess for basal effects of reward or punishment on the previous trial, VEH-session data were analysed for OL differences using paired $t$-tests. When assessing CDZ effects, behaviours occurring post-reward or post-punishment were analysed in a Dose $\mathrm{x} O L$ on subsequent trial (FR2-R/P, FR20-R) LMM model. In the case of significant main or interaction effects of fixed effects factors, post hoc testing was conducted using the least significant difference test. Statistical significance was set at $\mathrm{p} \leq 0.05$ (two-tailed). Data are reported as mean \pm standard error (SE).

\section{RESULTS}

\section{One-lever reward test}

To investigate whether CDZ altered operant responding under reward-only conditions, which could confound interpretation of $\mathrm{CDZ}$ effects under conflict conditions as anxiolytic, mice were first tested with 40 trials of FR1 leading to a sucrose pellet at $p=1$. Mice were allocated to a CDZ dose (VEH, 7.5, $15 \mathrm{mg} / \mathrm{kg}, \mathrm{n}=6$ per group) administered $30 \mathrm{~min}$ prior to testing on each of three consecutive days, 
followed by a further such reward test without drug on the following day. Analysing the 3 days with CDZ administration, there was no effect of Dose or Day on test duration ( $p \geq 0.31$, Fig. $3 A$ ) or postreward pause (PRP) ( $p \geq 0.13$, Fig. 3B). When analysis also included day 4 (no drug), for test duration there was a Dose $x$ Day interaction effect $(F(6,45)=2.82$, $p<0.03$, Fig. $3 A)$ : on day 4, mice in the 7.5 and $15 \mathrm{mg} / \mathrm{kg}$ groups had a longer test duration than on drug days and a longer test duration than did VEH mice. There was also a Dose $x$ Day interaction effect for $\operatorname{PRP}(F(6,45)=2.54, p<0.04$, Fig. 3B): on day 4, mice in the 7.5 and $15 \mathrm{mg} / \mathrm{kg}$ groups had longer PRP than on drug days and mice in the $7.5 \mathrm{mg} / \mathrm{kg}$ group had longer PRP than did VEH mice $(p<0.05)$; there was no significant effect of CDZ dose on PRP on days 1-3 ( $p \geq 0.11)$. Therefore, whilst there was no CDZ effect on operant responding for reward, withdrawal of $C D Z$ on day 4 resulted in a decrease in operant responding including increased response latency.

(FIGURE 3 ABOUT HERE)

\section{One-lever operant conflict test (1LOC test)}

In the same mice and starting 10 days after the last CDZ administration, we next compared behaviour in the one-lever reward (1LR) test and the one-lever operant conflict (1LOC) test using a VR2-10 schedule in both tests. Specifically, we compared the mean scores of mice $(N=18)$ in two $1 \mathrm{LR}$ tests each comprising $40 \mathrm{R}$ trials with their mean scores in the $20 \mathrm{R} / \mathrm{P}$ trials in two $1 \mathrm{LOC}$ tests (comprising $10 \mathrm{R} 1+20 \mathrm{R} / \mathrm{P}+10 \mathrm{R} 2$ trials). The PRP was longer In the $1 \mathrm{LOC} R / \mathrm{P}$ trials than the $1 \mathrm{LR}$ trials $(t(17)=-4.27, p<0.001$, Fig. $4 \mathrm{~A})$ as was the OL press interval $(\mathrm{LPI})(t(17)=-2.16, \mathrm{p}<0.05$, Fig. 4B). In other words, mice took more time to initiate responding (longer latency) and more time between responses (less vigour), in trials where the operant outcome could be either sucrose or footshock, compared with sucrose only trials.

We then investigated the effects of CDZ in the 1 LOC test using a latin square design. In contrast to the $\mathrm{R}$ tests where mice had not yet experienced footshock, CDZ already affected behaviour in the R1 phase of the 1LOC test (Table 1): thus, both PRP (VEH: $14.9 \pm 5.0 \mathrm{~s}, \mathrm{CDZ} 7.5: 4.5 \pm 1.0 \mathrm{~s}, \mathrm{CDZ} 15: 4.5 \pm 1.0$ s) and LPI (VEH: $1.2 \pm 0.1 \mathrm{~s}, \mathrm{CDZ} 7.5: 0.7 \pm 0.1 \mathrm{~s}, \mathrm{CDZ} 15: 0.6 \pm 0.1 \mathrm{~s})$ were shorter under CDZ compared to VEH. In the conflict (20 R/P) trials, for pause (Fig. 4C, Table 1) there was a trial type $x$ CDZ interaction: in VEH sessions the post-punishment pause was longer than the post-reward pause, whereas in CDZ sessions PPP and PRP were short and similar. For LPI (Fig. 4D, Table 1) there was also a trial type $x$ CDZ interaction: in VEH sessions LPI was longer after punishment than after reward, whereas in CDZ sessions the post-punishment LPI was short and similar to that which pertained post-reward in both VEH and CDZ sessions. These CDZ effects were not dose-dependent, as indicated by post hoc tests. The effects of the previous trial type and of CDZ on post-reward and post-punishment behaviour in the 1 LOC test are summarised in Table 2. 
(FIGURE 4 ABOUT HERE)

(TABLE 1 ABOUT HERE)

\section{Two-lever operant conflict test (2LOC test)}

The 2LOC testing was conducted with an independent sample of mice. In this test, we first investigated effects of footshock amplitude on choice behaviour, to establish the appropriate footshock amplitude to use for each mouse in the study of CDZ effects. To this end, all mice were run in three 2LOC tests, one each at footshock amplitude 0, 0.1 and $0.15 \mathrm{~mA}$. Number of completed trials at each OL (Fig. 5A) depended on footshock amplitude (interaction amplitude $x \mathrm{OL}, \mathrm{F}(4,153)=16.44, \mathrm{p}<0.0001$ ): at intensities 0 and $0.1 \mathrm{~mA}$, on average mice selected the FR2-R/P considerably more often than the FR20$\mathrm{R}$, whilst at $0.15 \mathrm{~mA}$ responding on the two OLs was equable. PRP increased with footshock amplitude and was longer when FR2O-R was chosen (Fig. 5B, Table 1). Post-reward LPI increased as amplitude increased, and at similar absolute levels on both OLs (Fig. 5C, Table 2). PPP increased with amplitude and was longer when FR20-R was chosen (Fig. 5D, Table 2). Post-punishment LPI was not influenced by amplitude or OL (Fig. 5E). In absolute terms, PP-LPI was approximately twice as long as PR-LPI, and at each OL. To maximise conflict in the subsequent study of CDZ effects, each mouse was tested at the lower footshock amplitude at which it exhibited the shift to equable responding at the FR20-R and FR2-R/P: for 5 mice this was at $0.1 \mathrm{~mA}$ and for the remaining 13 mice at $0.15 \mathrm{~mA}$.

(FIGURE 5 ABOUT HERE)

(TABLE 2 ABOUT HERE)

In the CDZ experiment, firstly, to assess the intrinsic effects of previous trial outcome, i.e. reward or punishment, on subjects' choice, latency and vigour behaviour, paired analysis of VEH session data was conducted. For response choice (Fig. 6B), after reward there was no consistent difference in the number of choices of FR2-R/P compared with FR20-R $(p=0.14)$, and the same was the case after punishment $(p=0.97)$. For response latency (Fig. 6C/E), PPP was greater than PRP, both at $F R 2-R / P(t(12)=-2.63, p<0.03)$ and FR20-R $(t(9)=-2.34, p<0.05)$. For response vigour (Fig. 6D/F), this was reduced $P P$ versus $P R$ at $F R 2-R / P(t(13)=-2.54, p<0.03)$ whereas at $F R 20-R$ response vigour was similar PP and PR ( $p=0.98)$. These VEH session findings are summarised in Table 2.

Turning to the comparison of sessions conducted with VEH, CDZ 7.5 and CDZ 15, for the number of trials completed (Fig. 6A) there was no effect of CDZ ( $p=0.14)$. There was a main effect of OL, with more FR2-R/P trials than FR20-R trials completed, and only a few uncompleted (failed) trials $(F(2,144)=40.23, p<0.0001)$. For response choice, latency and vigour, post-reward and postpunishment behavioural scores were analysed separately using a Dose $\mathrm{x}$ OL on subsequent trial model. 
For choice of $\mathrm{OL}$ in PR trials (Fig. 6B, Table 1) there was no dose main effect whilst there was a main effect of OL with mice choosing to complete more FR2-R/P than FR20-R trials. For PP trials (Fig. 6B, Table 1) there was a dose main effect with CDZ at both doses increasing the total number of choices made compared with VEH, and there was a main effect of OL with mice choosing to complete more FR2-R/P than FR20-R trials. The choice data were also analysed using the proportion of PR and PP trials at which FR2-R/P was chosen in a Dose $x$ Previous outcome LMM. There was no effect of CDZ dose $(p=0.82)$; there was a main effect of previous outcome with the probability that mice chose $F R 2-R / P$ on the next trial being higher PR $(0.70 \pm 0.05)$ than $P P(0.53 \pm 0.05)(F(1,82)=5.59, p<0.02)$. Returning to the Dose $x$ OL on subsequent trial analyses, for response latency, after reward trials (Fig. 6C, Table 1) there was a main effect of CDZ with the PRP shorter in CDZ compared with VEH sessions at both OLs; there was a main effect of OL with a shorter PRP at FR2-R/P than FR20-R. For response latency after punishment trails (Fig. 6E, Table 1) there was a main effect of CDZ with the PPP shorter in CDZ compared with VEH sessions at both OLs; there was no effect of OL. For response vigour, after reward trials vigour was not significantly affected by CDZ at either OL (Fig. 6D, Table 1). For response vigour after punishment trials there was a Dose $\mathrm{x}$ OL choice interaction, with CDZ leading to an increase in vigour at FR2-R/P specifically (Fig. 6F, Table 1). None of the CDZ effects obtained were dosedependent, as indicated by post hoc tests. The effects of CDZ on PR and PP behaviour relative to FR2$\mathrm{R} / \mathrm{P}$ and FR2O-R in the 2LOC test are summarised in Table 2.

(FIGURE 6 ABOUT HERE)

Following completion of the study of CDZ effects in the 2LOC test, in these same mice we assessed CDZ effects on non-conflict reward-directed behaviour and on pain sensitivity. Mice were allocated at random to CDZ dose groups and a test was conducted using FR20 only i.e. no choice and no punishment trials. There was no significant effect of Dose on any parameter, including number of completed trials (VEH: $32 \pm 13,7.5: 40 \pm 0,15: 35 \pm 12, p=0.40$ ), PRP (VEH: $14.9 \pm 4.5$ s, $7.5: 6.2 \pm 2.5 \mathrm{~s}, 15$ : $8.9 \pm 10.2 s, p=0.14)$ and LPI (VEH: $0.19 \pm 0.08 s, 7.5: 0.13 \pm 0.03 s, 15: 0.14 \pm 0.05 s, p=0.25)$. To assess nociceptive effects of CDZ we conducted a hot plate test, with each mouse tested at one dose. There was a significant effect of Dose on pain sensitivity, measured as latency to lift a fore or hind limb $(F(2,14)=4.1, p<0.05)$. Whilst neither dose resulted in an effect relative to VEH mice $(30.2 \pm 6.7 \mathrm{~s}), 15$ $\mathrm{mg} / \mathrm{kg} \mathrm{CDZ}(22.5 \pm 8.0 \mathrm{~s}$ ) led to a lower response latency than did $7.5 \mathrm{mg} / \mathrm{kg} \mathrm{CDZ}(33.0 \pm 2.7 \mathrm{~s})$, suggesting increased nociception at this higher dose.

\section{DISCUSSION}

The aim of this study in mice was to establish operant tests that allow for the study of conflicting actions as well as for their separation into specific components that may serve different goals, namely 
choice, latency to initiate action (behavioural inhibition), and intervals between responses once a choice and action have been initiated (action vigour). Previous human studies have suggested that these response components may be dissociable (Bach 2015; Khemka et al., 2017). We investigated the effects of the benzodiazepine chlordiazepoxide on these separate components. In moderately foodrestricted mice, sucrose pellet and footshock were used as reward and punishment, respectively, for active approach behaviour. In a one-lever conflict test, mice could obtain reward only by incurring a threat of punishment, whereas in the two-lever test they could choose between a combination of loweffort reward-punishment or high-effort reward. We found that both tests were sensitive to $C D Z$, although CDZ effects depended on both the measure in question and the outcome of the directly preceding trial. In the $1 \mathrm{LOC}$ test, CDZ reduced response latency after reward and punishment, and increased response vigour after punishment specifically. In the 2LOC test, mice preferred the loweffort reward-punishment choice, and particularly post-reward. CDZ did not affect which lever was chosen post-reward or -punishment whilst it did increase the absolute number of choices of both levers post-punishment; it reduced response latencies on both levers and both post-reward and postpunishment, and it increased response vigour on the low-effort reward-aversion lever and after punishment specifically. However, it had no impact on the differential choice between the two levers. As such, this study presents a mouse operant test for the translational study of choice conflict in which different components of anxiety-like behaviour are measured. The findings that the effects of CDZ on choice and vigour were dependent on immediately preceding events whereas its effects on response latency were relatively consistent across test conditions, highlight the importance of analysing these anxiety components separately.

In the 1LOC test on a VR2-10 schedule, introducing $1 \mathrm{~s}$ of $0.1 \mathrm{~mA}$ footshock at $\mathrm{p}=0.3$ during trials 11-30 ( $\mathrm{R} / \mathrm{P}$ trials) was sufficient to increase response latency and decrease response vigour relative to reward-only test conditions. Within these $\mathrm{R}+\mathrm{P}$ trials, response latency was higher and response vigour lower following punishment trials in comparison with reward trials. With respect to CDZ effects, response latency was disinhibited following either reward or punishment in the previous trial, whilst response vigour was increased following punishment specifically (Table 1). Therefore, reinitiation of responding was sensitive to the anxiolytic regardless of the immediately preceding experience, suggesting that the overall level of recent experiences was contributing to this decision. In contrast, once initiated, response vigour was high following recent reward and not inhibited by anxiety, whereas it was low following recent aversion and responsive to the anxiolytic. When the 1LOC test was conducted repeatedly, CDZ also reduced PRP and LPI during the reward-only phase (trials 1-10) of the test, whereas it was without effect on these measures when the mice had not yet experienced aversion in the test. These findings suggest that experiencing footshock in the test context resulted in an anxiety-like state even in the initial, reward only phase of subsequent tests. The test set-up differs 
from that of the Geller-Seifter test: the latter also uses one operant lever, but the reward-only and reward-aversion test phases are signalled by changing illumination and background noise. In mice, diazepam increased the percentage of operant responses during the reward-aversion period relative to total responses (Lu et al., 2011; Varty et al., 2005). It is noteworthy that the food restriction (80-85\% baseline) and footshock amplitude (0.5 s x $0.3 \mathrm{~mA}$ ) applied in mouse studies with the Geller-Seifter test were more severe than in the present study (Lu et al., 2011; Varty et al., 2005). It will be interesting to investigate the sensitivity of the Geller-Seifter test for the detection of anxiolytic effects on response latency and vigour.

In the $2 \mathrm{LOC}$ test, we first compared different footshock amplitudes to establish the lowest amplitude at which each mouse demonstrated a loss of preference for the low-effort rewardpunishment lever relative to the high-effort reward lever; subsequently, each mouse was tested for CDZ effects at this amplitude. In this test, mice not only had to decide on whether or not to approach and respond at a lever but also at which lever to respond. That this resulted in additional decision requirements is indicated by the increase in response latency, particularly post-punishment, in the $2 \mathrm{LOC}$ test versus the $1 \mathrm{LOC}$ test under VEH conditions. This is consistent with the $2 \mathrm{LOC}$ test being particularly anxiogenic, i.e. conflict inducing, and therefore sensitive to the detection of anxiolytic compounds. It needs to be noted, however, that the majority of mice received $0.15 \mathrm{~mA}$ footshock in the 2LOC test whereas all mice received $0.1 \mathrm{~mA}$ footshock in the $1 \mathrm{LOC}$ test, and the increased behavioural inhibition in the 2LOC test could be partly explained by this quantitative difference in punishment.

Under basal (vehicle) conditions, there was no significant choice preference for one lever over the other following either reward or punishment. Response latency was substantially longer postpunishment than post-reward and in each state the latency was similar at both levers. Response vigour was lower post-punishment than post-reward at the FR2-R/P lever, whilst it was similar regardless of previous outcome at the FR2O-R lever. Therefore, in their basal state and with high feeding motivation, when a low-effort/high-risk decision results in punishment there is an increase in decision time at the next trial and the size of this increase is also similar on both levers. Response vigour during loweffort/high-risk behaviour, when there is a risk of further punishment, is reduced by recent punishment. Therefore, whilst response latency and vigour are both impacted by the valence of the immediate environment, these actions are occurring in a sequence of on-going decision-making and, accordingly, are independent of each other. For example, having just been punished, mice take longer to initiate subsequent responding at either lever; if they respond on the low-effort/high-risk lever they do so with low vigour reflecting recent experience, but if they respond on the high-effort/no-risk lever they do so with high vigour because their environment is now safe. By measuring each of these 
decision-making steps, the 2LOC test is allowing for the composite study of the components of anxietylike behaviour.

Concerning the effects of CDZ on these response parameters, with respect to lever choice, CDZ efficacy was, as expected, most pronounced in the relatively anxiogenic state of post-punishment, when it increased the overall number of choices at either lever. For response latency, CDZ disinhibited response onset at both levers and both post-reward and post-punishment; post-punishment it ameliorated the long latency and post-reward it reduced the latency at the low-effort/high-risk lever in particular. For response vigour, CDZ increased this in the anxiogenic state of post-punishment responding at the low-effort/high-risk lever. Therefore, $C D Z$ is influencing behaviour at each of the decision-making steps of the 2LOC test, and appears to do so by ameliorating the impact of both previous punishment and potential future punishment on on-going behaviour. Thus, it increases the overall lever choices post-punishment, reduces response latency at the low-effort/high-risk lever in particular, and increases vigour of post-punishment low-effort/high-risk lever responding specifically. Such translational study of the relevance of prior and potential future aversion for distinct components of conflict behaviour, and the psychopharmacological regulation thereof, could well be valuable in the study of anxiety neurobiology and of new molecular targets for novel anxiolytic treatments. Brain regions implicated in the regulation of conflict decision-making and behaviour include the basolateral amygdala (Jean-Richard-Dit-Bressel and McNally 2015) and the septohippocampal system (behavioural inhibition system: (Gray and McNaughton 2000)). Lesioning and pharmacological inhibition of these regions exert anxiolytic effects in conflict tests. Furthermore, it may be interesting to test large numbers of mice to investigate for systematic individual differences in the relationships between the test components, as conducted with other anxiety tests (Lopez-Aumatell et al., 2008; Rodgers and Johnson 1995).

Previous studies of rodent anxiety in operant conflict tests have identified the efficacy of CDZ. For example, in rat studies, CDZ increased punished responding in the Geller-Seifter test (Britton et al., 1985) and in an ascending footshock single-lever operant test (Evenden et al., 2009). Importantly, in the present study we also demonstrate that $C D Z$ was without effects on both operant responding for reward in the absence of conflict and on pain sensitivity. Repeated CDZ did result in a withdrawal effect in terms of reduced responding for reward, suggesting induction of an anhedonic state. It is also important to note that the present study was limited by the absence of a dose-dependent effect of CDZ on any measure, and future studies will need to include lower doses, therefore.

Comparing the present findings with the $2 \mathrm{LOC}$ test with relevant published findings, in a twolever "risky decision-making task" (RDT) conducted with rats, one lever delivered 1 pellet and the other lever delivered $>1$ pellet and also footshock at different probabilities, and FR1 was used at both levers (Shimp et al., 2015). As in the 2 LOC test, there was a longer response latency at the potentially 
punished lever. The absolute response latency durations were considerably greater in the present study: this could indicate that the two mutually exclusive outcomes were rather more equable in the $2 \mathrm{LOC}$ test than the RDT. Smaller value difference would translate into longer decision times in several theoretical frameworks: for example, in drift-diffusion models of choice which are considered to describe value-based decision-making (Tajima et al., 2016) and in traditional conflict models which predict that equable outcomes result in more conflict anxiety that requires more time for conflict resolution (Gray and McNaughton 2000).

To summarise, the present study demonstrates the high potential of mouse operant choice conflict tests, and particularly those requiring conflict resolution between equable alternatives of loweffort reward-punishment and high-effort reward. Such tests highlight the importance of both immediately prior and potential future aversive events to the causation of conflict anxiety and the advantage of studying the distinctive, sequential processes that together constitute conflict decisionmaking and behaviour. They can be utilised for the translational study of anxiety-like behaviour, the underlying neurobiology thereof, and the study of the acute, chronic and withdrawal effects of anxiolytic drugs and novel putative anxiolytic compounds.

\section{ACKNOWLEDGEMENTS}

We are grateful to Björn Henz and Alex Osei for animal care. The experiments comply with the current laws of Switzerland. This research was funded in part by the Swiss National Science Foundation (grant 31003A-160147 to CRP). ES is an employee of TSE Systems, Germany. All remaining authors declare no competing interests. 


\section{Figure captions}

Figure 1. Apparatus for the two operant anxiety tests.

(A) Photograph of the operant conflict test apparatus.

(B) Apparatus schema for the single-lever operant conflict test (1LOC test). At the onset of each conflict trial the operant lever (OL) was extended into the chamber; on a variable ratio (VR) 2-10 schedule, attaining criterion resulted in either sucrose pellet reward $(R)$ at probability $(p)=0.7$ per trial or footshock $(1 \mathrm{~s} \times 0.1 \mathrm{~mA})$ punishment $(P)$ at $p=0.3$ per trial. In $R$ trials, attaining criterion was signalled by $1 \mathrm{~s}$ tone, the OL was retracted, and the vertical door in the feeder port (FP) was opened and a sucrose pellet delivered (R-VR2-10). Following pellet retrieval the FP door closed and after a time out of $5 \mathrm{~s}$ the next trial was initiated. In P trials the footshock was delivered immediately (P-VR2-10) and the OL was retracted, and after a time out of $5 \mathrm{~s}$ the next trial was initiated.

(C) Apparatus schema for the two-lever operant conflict test (2LOC test). At the onset of each conflict trial both operant levers (OL1, OL2) were extended into the chamber. If two lever presses were made first at OL1 (FR20-R): OL2 was retracted, pressing OL1 a further 18 times resulted at $p=1$ in a $1 \mathrm{~s}$ tone, FP1 was opened and a sucrose pellet delivered and collected. If two lever presses were made first at OL2 (FR2-R/P): both OLs were retracted, at $p=0.7$ per trial attaining criterion was signalled by the $1 \mathrm{~s}$ tone, FP2 was opened and a sucrose pellet delivered and collected, and at $p=0.3$ per trial a $1 \mathrm{~s} \times 0.1$ $0.15 \mathrm{~mA}$ footshock was delivered. After R or P there was a $5 \mathrm{~s}$ time out followed by the next trial. After the first press at OL1 or OL2 the maximum trial duration was $40 \mathrm{~s}$ and failure to reach FR20 at OL1 or FR2 at OL2 resulted in retraction of both OLs and initiation of a time out ("failed trial").

Figure 2. Flow chart showing the stages of training undergone by all mice, and the training and testing stages specific to mice studies in the $1 \mathrm{LOC}$ test or $2 \mathrm{LOC}$ test.

Figure 3. Effects of i.p. chlordiazepoxide (CDZ) on behaviour in a single-lever, fixed-ratio 1 reward test. Mice $(n=18)$ were allocated to groups (counter-balanced for post-reinforcement pause scores at completion of training) that received vehicle (VEH), 7.5 or $15 \mathrm{mg} / \mathrm{kg}$ CDZ on each of 3 consecutive days prior to a reward test on each of these days and the following day. (A) Test duration: there was no CDZ effect on days 1-3 whereas test duration was increased in CDZ versus VEH mice on day 4. (B) Postreward pause: there was no CDZ effect on days 1-3 whereas PRP was increased in CDZ versus VEH mice on day 4. Values are mean +/- SE. $p$ values are for LMM; a vs b $p<0.05$ for CDZ dose using the LSD post hoc test.

Figure 4. Comparison of behaviour in a single-lever reward $(R)$ test versus the single-lever operant conflict (1LOC) test (A-B) and effects of chlordiazepoxide (CDZ) on behaviour in the 1 LOC test (C-D). 
(A-B) Mice $(n=18)$ were each given two $R$ tests, each comprising 40 variable-ratio 2-10 (VR2-10) trials for sucrose pellet at $p=1$, and two 1 LOC tests, each comprising 10 VR2-10 trials with sucrose reward at $p=1,20$ VR2-10 trials with sucrose reward at $p=0.7$ and footshock punishment at $p=0.3(R / P)$, and another 10 VR2-10 trials with sucrose reward at $p=1$. (A) Mean post-reward pause (PRP) in the $R$ test versus R/P trials of the $1 L O C$ test. (B) Mean lever press interval (LPI) in the R test versus R/P trials of the $1 \mathrm{LOC}$ test. $p$ values are for the paired $t$-test.

(C-D) Anxiolytic effects of i.p. CDZ in the 20 reward or punishment (R/P) conflict trials of the 1 LOC test. The same mice as in (A-B) each received each of CDZ doses $0,7.5$ and $15 \mathrm{mg} / \mathrm{kg}$ using a latin square design with 2-3 days between consecutive test days. (C) Mean pause prior to initiating next trial according to whether this was post-reward (PRP) or post-punishment (PPP). (D) Mean lever press interval (LPI) in trials according to whether these were post-reward (PR) or post-punishment (PP). Values are mean +/- SEM. $p$ values are for LMM followed, where valid, by LSD post hoc tests: $a$ vs $b$ $p<0.05$ for CDZ dose; $* * * * p<0.0001$ for trial type within dose.

Figure 5. Effects of footshock amplitude on behaviour in the two-lever operant conflict test. Mice ( $n=18$ ) were tested sequentially and on separate days in the $2 \mathrm{LOC}$ test using either $0,0.1$ or $0.15 \mathrm{~mA}$ footshock in punishment trials. Each test comprised 40 trials maximum or 40 min maximum, whichever occurred first. (A) Number of trials per session at the FR2-R/P lever, FR20-R lever, or neither lever (failed trials). (B) Mean post-reward pause according to whether the selected lever was FR2-R/P or FR20-R on the next trial. (C) Mean post-reward lever press interval according to whether the selected lever was FR2-R/P or FR20-R on the next trial. (D) Mean post-punishment pause according to whether the selected lever was FR2-R/P or FR20-R on the next trial. (E) Mean post-punishment lever press interval according to whether the selected lever was FR2-R/P or FR20-R on the next trial. Values are mean +/- SEM. $p$ values are for LMM followed, where valid, by LSD post hoc tests: a vs b vs c or d vs e $p<0.05$ for footshock amplitude main effect or within trial type; ${ }^{*} p<0.05, * * p<0.01, * * * * p<0.0001$ for trial type main effect or for trial type within footshock amplitude.

Figure 6. Anxiolytic effects of i.p. CDZ on behaviour in the two-lever operant conflict test. Mice $(n=17$, same as in Fig. 5) each received each of the CDZ doses $0,7.5$ and $15 \mathrm{mg} / \mathrm{kg}$ using a latin square design with 2-3 days between consecutive test days. For each mouse the same footshock amplitude was used on each test day and whether this was 0.1 or $0.15 \mathrm{~mA}$ depended on whether the lower amplitude reduced responding at the FR2 operant lever in the experiment depicted in Fig. 5. (A) Number of trials per session at the FR2-R/P lever, FR20-R lever, or neither lever (failed trials). (B) Number of choices for each lever according to whether trial was post-reward or post-punishment. (C) Mean post-reward pause according to whether the selected lever was FR2-R/P or FR20-R on the next trial. (D) Mean post- 
reward lever press interval according to whether the selected lever was FR2-R/P or FR20-R on the next trial. (E) Mean post-punishment pause according to whether the selected lever was FR2-R/P or FR2O$\mathrm{R}$ on the next trial. (F) Mean post-punishment lever press interval according to whether the selected lever was FR2-R/P or FR20-R on the next trial. Values are mean +/-SEM. $p$ values are for LMM followed, where valid, by LSD post hoc tests: a vs b $p<0.05$ for CDZ dose; * $p<0.05, * * * p<0.001,{ }^{* * * *} p<0.0001$ for trial type main effect or trial type within CDZ dose. 


\section{REFERENCES}

Amemori, K., Amemori, S., Graybiel, A.M., 2015. Motivation and affective judgments differentially recruit neurons in the primate dorsolateral prefrontal and anterior cingulate cortex. J Neurosci 35, 1939-53.

Azzinnari, D., Sigrist, H., Staehli, S., Palme, R., Hildebrandt, T., Leparc, G., Hengerer, B., Seifritz, E., Pryce, C.R., 2014. Mouse social stress induces increased fear conditioning, helplessness and fatigue to physical challenge together with markers of altered immune and dopamine function. Neuropharmacology 85, 328-341.

Bach, D.R., 2015. Anxiety-Like Behavioural Inhibition Is Normative under Environmental ThreatReward Correlations. PLoS computational biology 11, e1004646.

Bach, D.R., Dayan, P., 2017. Algorithms for survival: a comparative perspective on emotions. Nature reviews. Neuroscience 18, 311-319.

Bach, D.R., Guitart-Masip, M., Packard, P.A., Miro, J., Falip, M., Fuentemilla, L., Dolan, R.J., 2014. Human hippocampus arbitrates approach-avoidance conflict. Curr. Biol. 24, 541-7.

Bach, D.R., Korn, C.W., Vunder, J., Bantel, A., 2018. Effect of valproate and pregabalin on human anxiety-like behaviour in a randomised controlled trial. Transl Psychiatry 8, 157.

Britton, K.T., Morgan, J., Rivier, J., Vale, W., Koob, G.F., 1985. Chlordiazepoxide attenuates response suppression induced by corticotropin-releasing factor in the conflict test. Psychopharmacology (Berl). 86, 170-4.

Calhoon, G.G., Tye, K.M., 2015. Resolving the neural circuits of anxiety. Nat. Neurosci. 18, 1394-404.

Coutinho, C.B., Cheripko, J.A., Carbone, J.J., 1969. Relationship between the duration of anticonvulsant activity of chlordiazepoxide and systemic levels of the parent compound and its major metabolites in mice. Biochem. Pharmacol. 18, 303-16.

Dawson, G.R., Tricklebank, M.D., 1995. Use of the elevated plus maze in the search for novel anxiolytic agents. TiPS 16, 33-36.

Evenden, J., Ross, L., Jonak, G., Zhou, J., 2009. A novel operant conflict procedure conflict procedure using incrementing shock intensities to assess the anxiolytic and anxiogeneic effects of drugs. Behav Pharmacol 20, 226-236.

File, S.E., Lippa, A.S., Beer, B., Lippa, M.T., 2004. Animal tests of anxiety. Current protocols in neuroscience Chapter 8, Unit 8.3.

Gray, J.A., Davis, N., Feldon, J., Rawlins, N.P., Owen, S.R., 1981. Animal models of anxiety. Prog NeuroPsychopharmacol 5, 143-157.

Gray, J.A., McNaughton, N., 2000. The Neuropsychology of Anxiety: an enquiry into the functions of the septo-hippocampal system, 2nd edn. Oxford University Press, Oxford 
Griebel, G., Holmes, A., 2013. 50 years of hurdles and hope in anxiolytic drug discovery. Nature reviews. Drug discovery $12,667-87$.

Ito, R., Lee, A.C., 2016. The role of the hippocampus in approach-avoidance conflict decision-making: Evidence from rodent and human studies. Behav Brain Res 313, 345-57.

Jean-Richard-Dit-Bressel, P., Killcross, S., McNally, G.P., 2018. Behavioral and neurobiological mechanisms of punishment: implications for psychiatric disorders. Neuropsychopharmacology $43,1639-1650$.

Jean-Richard-Dit-Bressel, P., McNally, G.P., 2015. The role of the basolateral amygdala in punishment. Learn Mem 22, 128-37.

Khemka, S., Barnes, G., Dolan, R.J., Bach, D.R., 2017. Dissecting the Function of Hippocampal Oscillations in a Human Anxiety Model. J Neurosci 37, 6869-6876.

Kirlic, N., Young, J., Aupperle, R.L., 2017. Animal to human translational paradigms relevant for approach avoidance conflict decision making. Behav Res Ther 96, 14-29.

Korn, C.W., Vunder, J., Miro, J., Fuentemilla, L., Hurlemann, R., Bach, D.R., 2017. Amygdala Lesions Reduce Anxiety-like Behavior in a Human Benzodiazepine-Sensitive Approach-Avoidance Conflict Test. Biol Psychiatry 82, 522-531.

Lopez-Aumatell, R., Guitart-Masip, M., Vicens-Costa, E., Gimenez-Llort, L., Valdar, W., Johannesson, M., Flint, J., Tobena, A., Fernandez-Teruel, A., 2008. Fearfulness in a large N/Nih genetically heterogeneous rat stock: differential profiles of timidity and defensive flight in males and females. Behav Brain Res 188, 41-55.

Lu, S.X., Higgins, G.A., Hodgson, R.A., Hyde, L.A., Del Vecchio, R.A., Guthrie, D.H., Kazdoba, T., McCool, M.F., Morgan, C.A., Bercovici, A., Ho, G.D., Tulshian, D., Parker, E.M., Hunter, J.C., Varty, G.B., 2011. The anxiolytic-like profile of the nociceptin receptor agonist, endo-8-[bis(2chlorophenyl)methyl]-3-phenyl-8-azabicyclo[3.2.1]octane-3-carboxami de (SCH 655842): comparison of efficacy and side effects across rodent species. Eur J Pharmacol 661, 63-71.

Rodgers, R.J., Cao, B.J., Dalvi, A., Holmes, A., 1997. Animal models of anxiety: an ethological perspective. Braz. J. Med. Biol. Res. 30, 289-304.

Rodgers, R.J., Johnson, N.J., 1995. Factor analysis of spatiotemporal and ethological measures in the murine elevated plus-maze test of anxiety. Pharmacol. Biochem. Behav. 52, 297-303.

Shimp, K.G., Mitchell, M.R., Beas, B.S., Bizon, J.L., Setlow, B., 2015. Affective and cognitive mechanisms of risky decision making. Neurobiol Learn Mem 117, 60-70.

Simon, N.W., Setlow, B., 2012. Modeling risky decision making in rodents. Methods Mol. Biol. 829, 16575.

Tajima, S., Drugowitsch, J., Pouget, A., 2016. Optimal policy for value-based decision-making. Nat Commun 7, 12400. 
Tovote, P., Fadok, J.P., Luthi, A., 2015. Neuronal circuits for fear and anxiety. Nature reviews. Neuroscience 16, 317-31.

Varty, G.B., Hyde, L.A., Hodgson, R.A., Lu, S.X., McCool, M.F., Kazdoba, T.M., Del Vecchio, R.A., Guthrie, D.H., Pond, A.J., Grzelak, M.E., Xu, X., Korfmacher, W.A., Tulshian, D., Parker, E.M., Higgins, G.A., 2005. Characterization of the nociceptin receptor (ORL-1) agonist, Ro64-6198, in tests of anxiety across multiple species. Psychopharmacology (Berl). 182, 132-43.

Vogel, J.R., Beer, B., Clody, D.E., 1971. A simple and reliable conflict procedure for testing anti-anxiety agents. Psychopharmacologia 21, 1-7. 
Figure 1

(A)

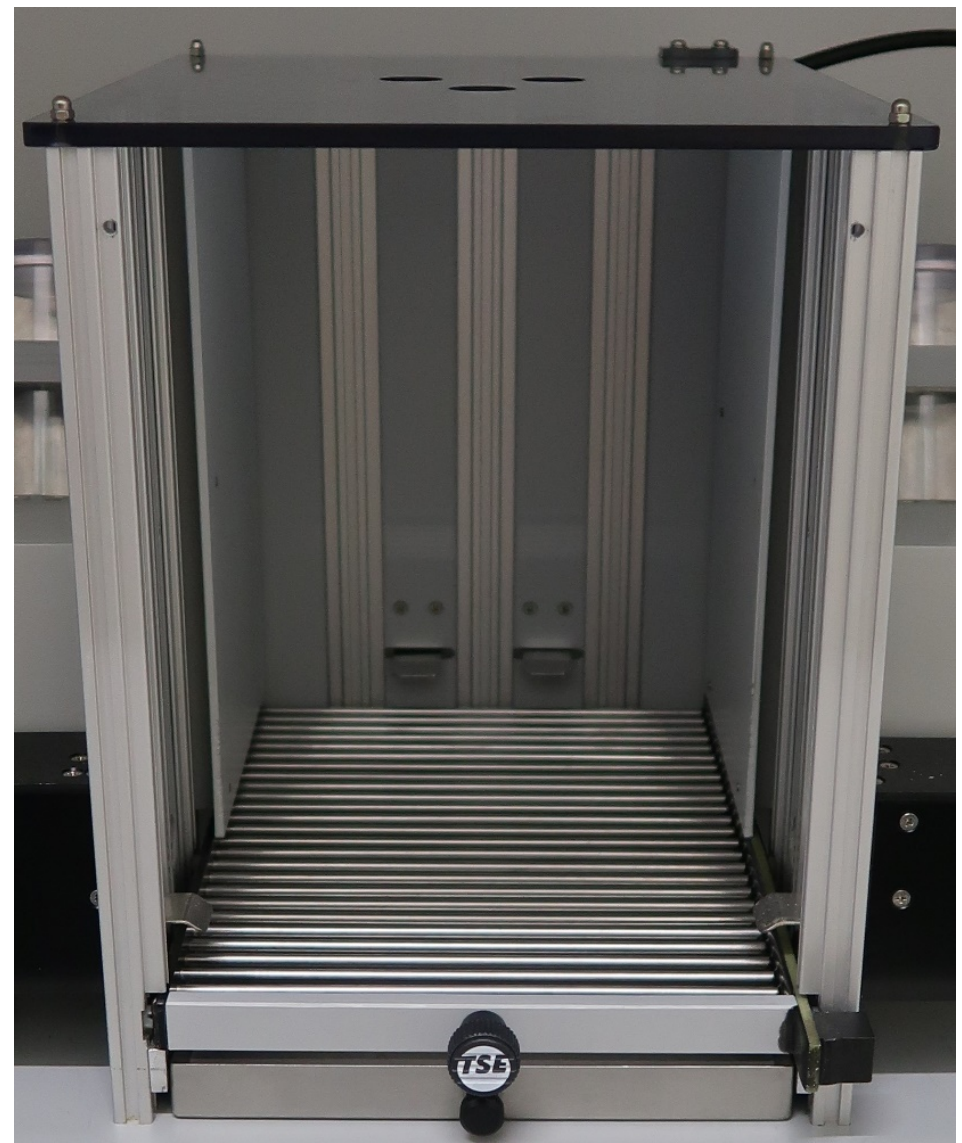

(B)

$$
\begin{aligned}
& \text { VR2-10 } \\
& R p=0.7 \\
& P p=0.3
\end{aligned}
$$

(C)

FR20-R

$\mathrm{R} p=1$

FR2-R/P

$R p=0.7$

$P p=0.3$
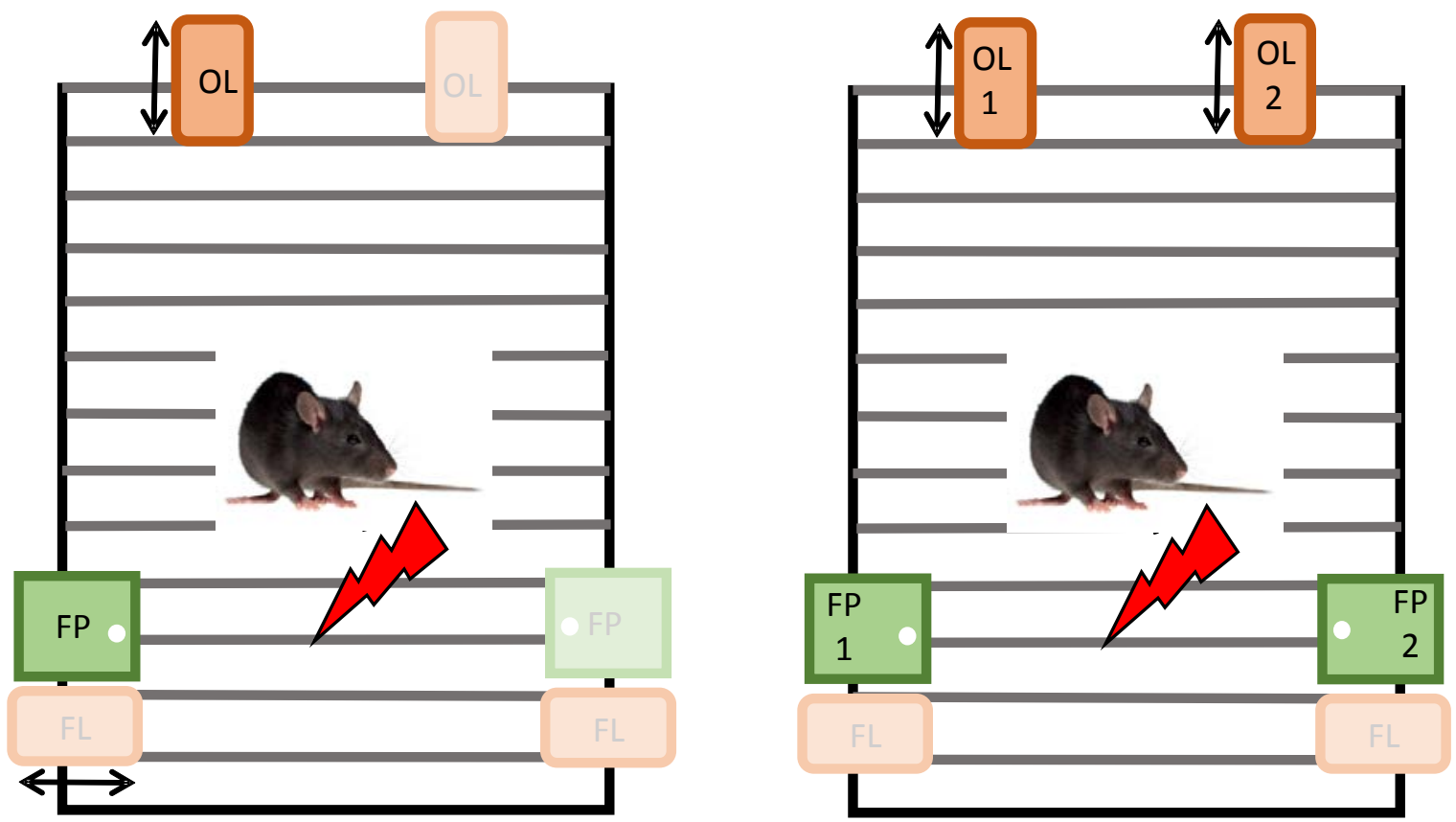


\section{Figure 2}

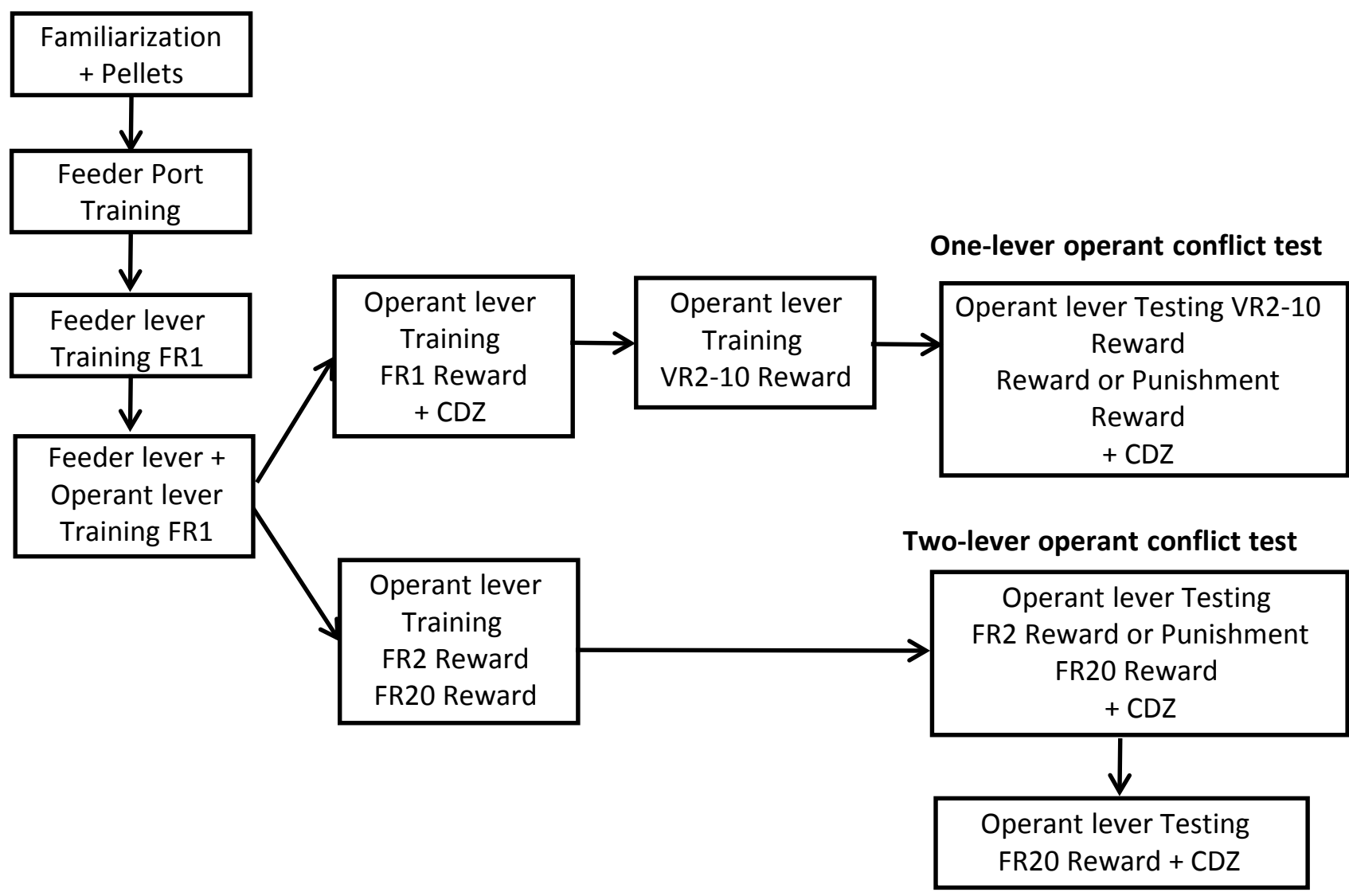


Figure 3

(A)

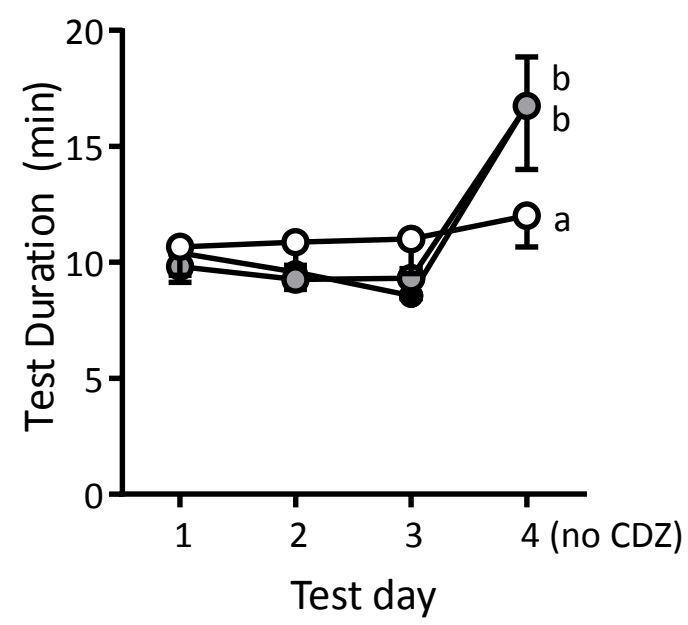

(B)

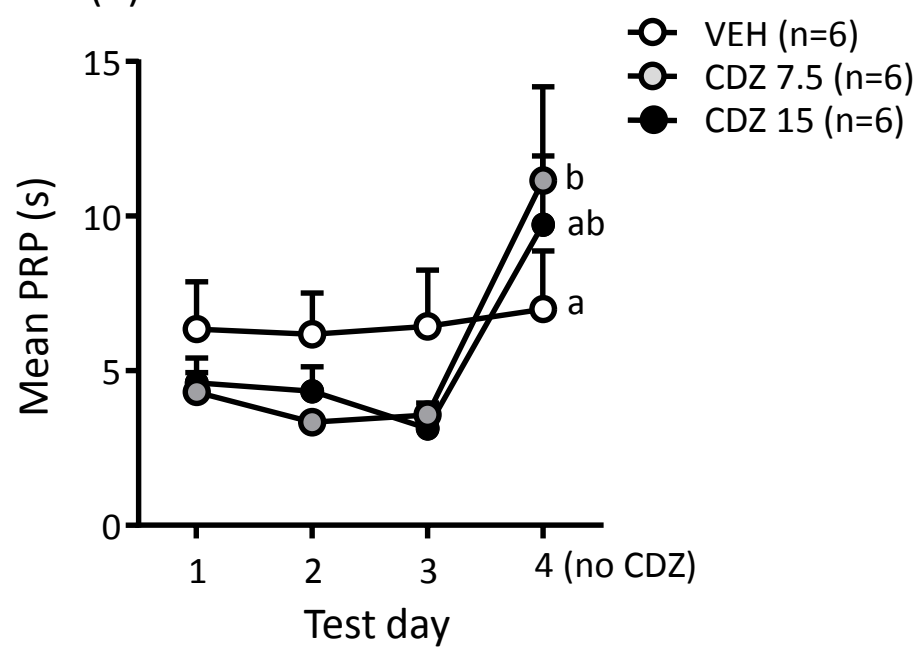


Figure 4

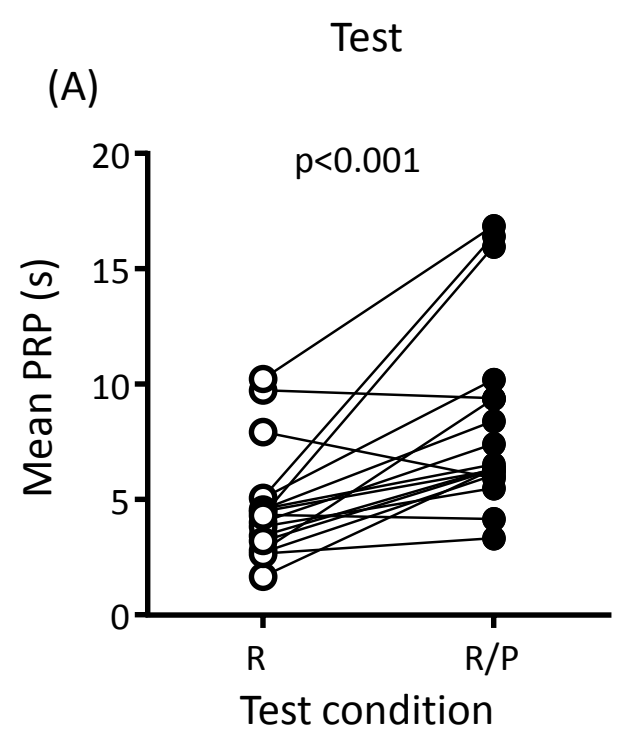

(B)

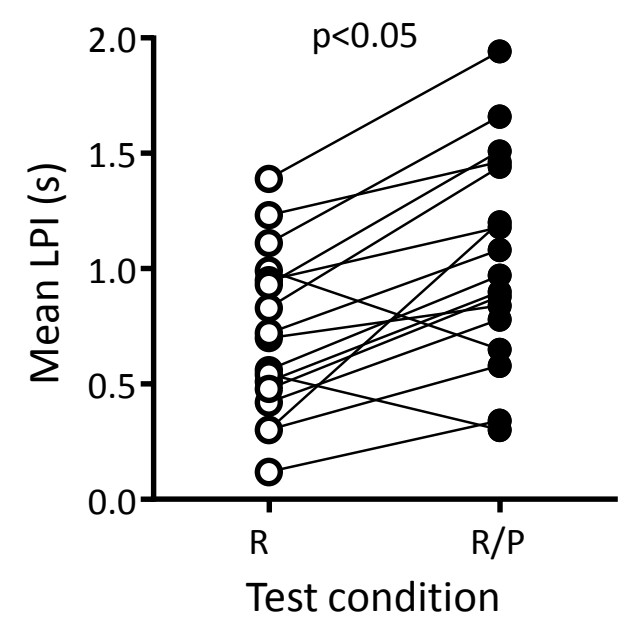

(C)

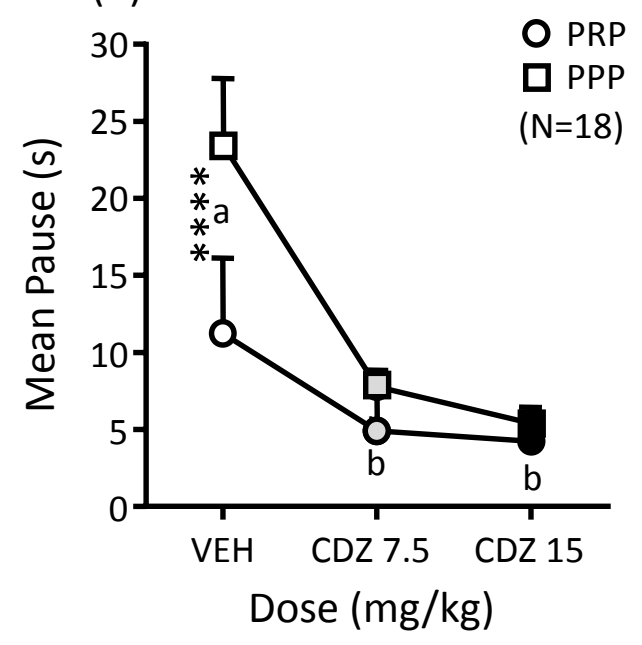

(D)

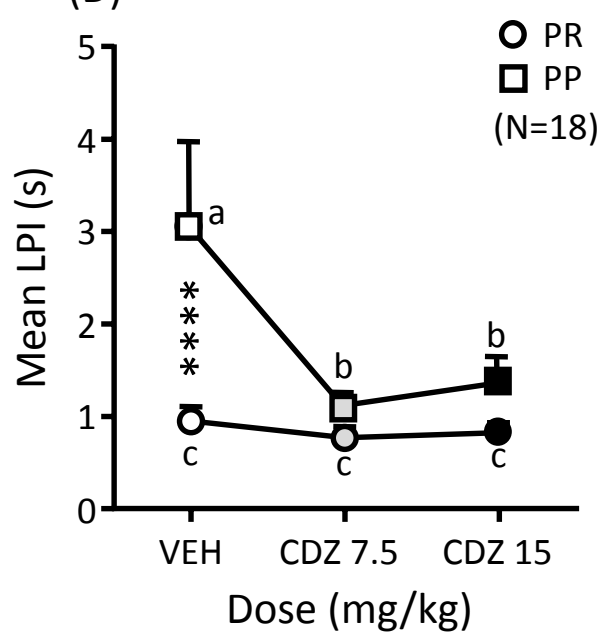


Figure 5
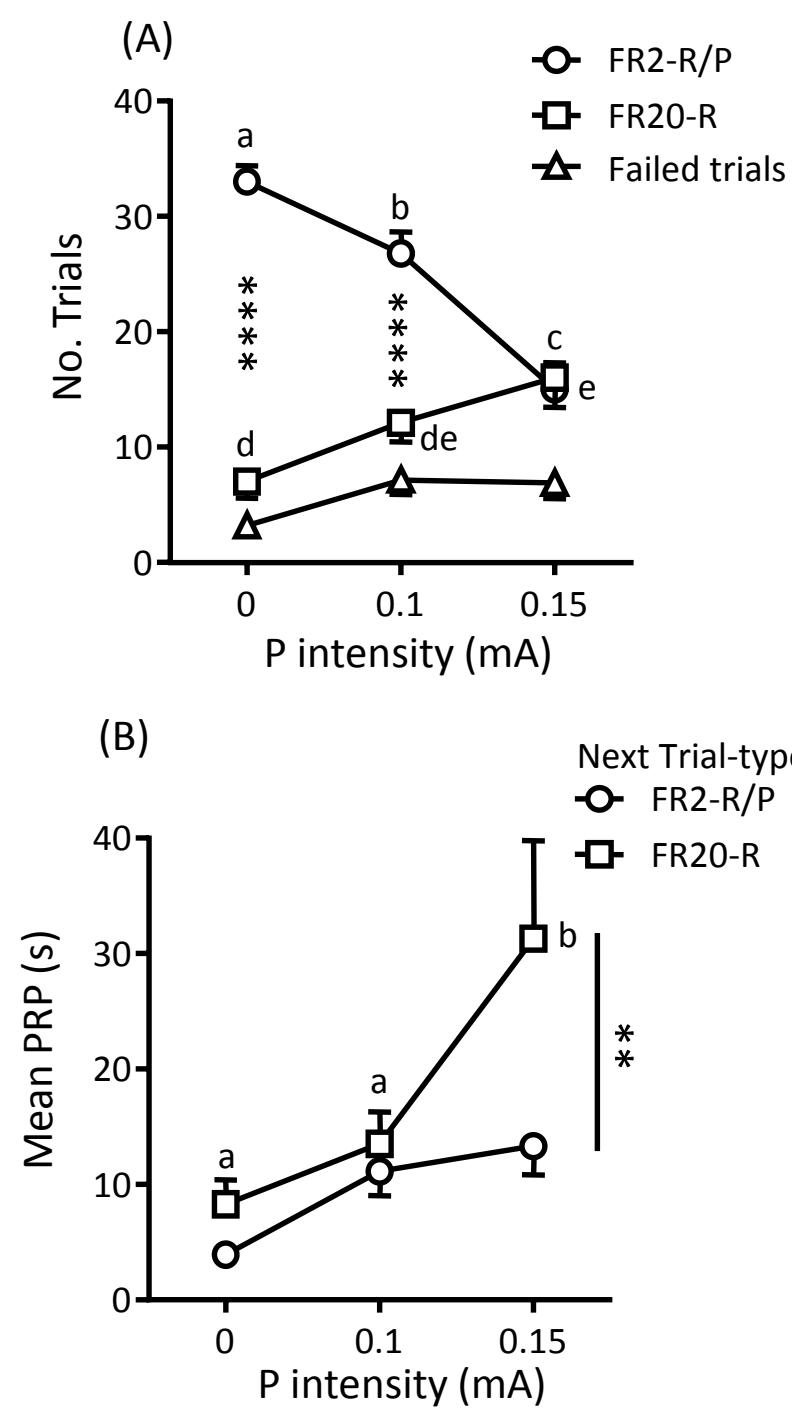

(D)
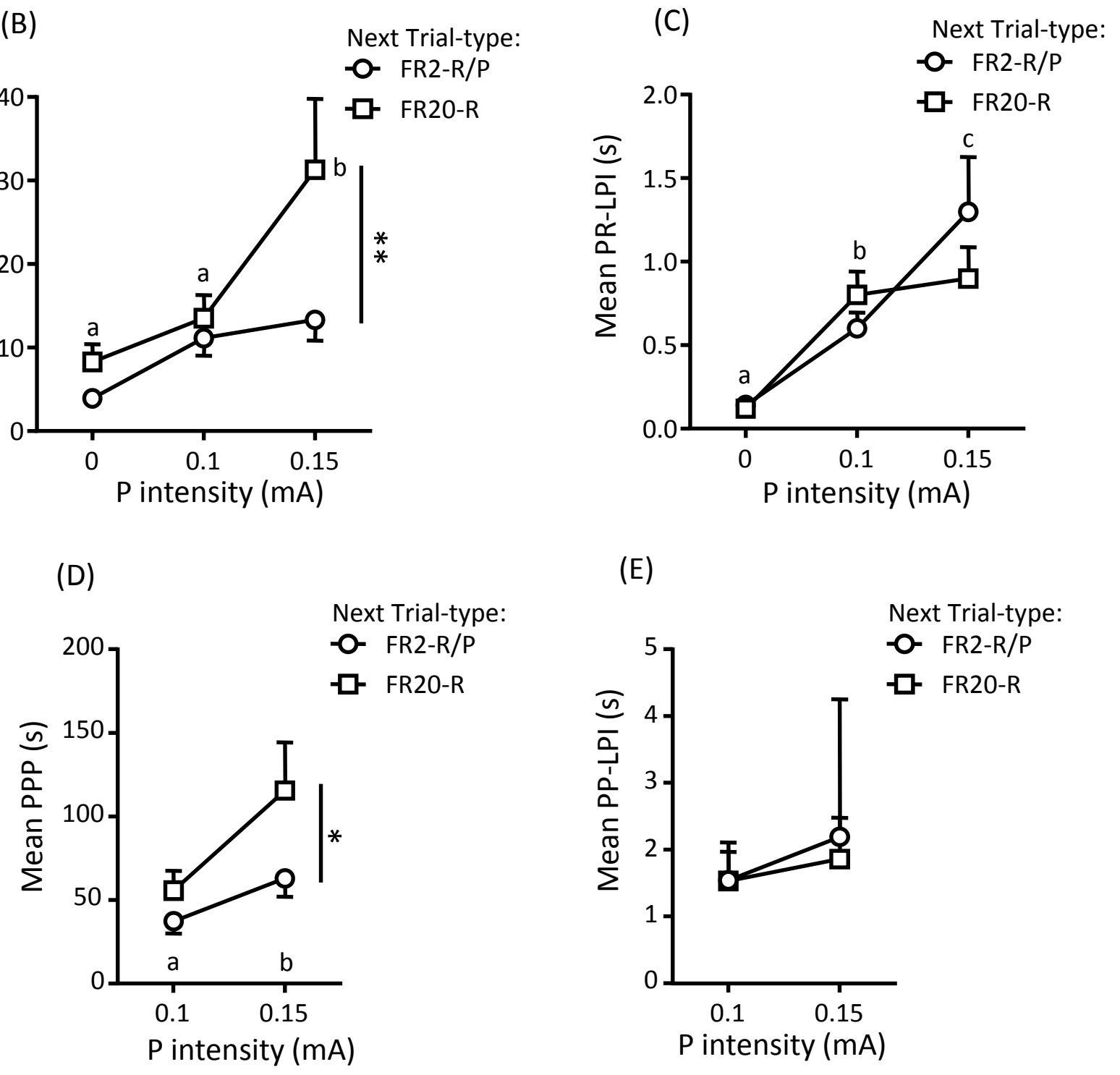

(E)

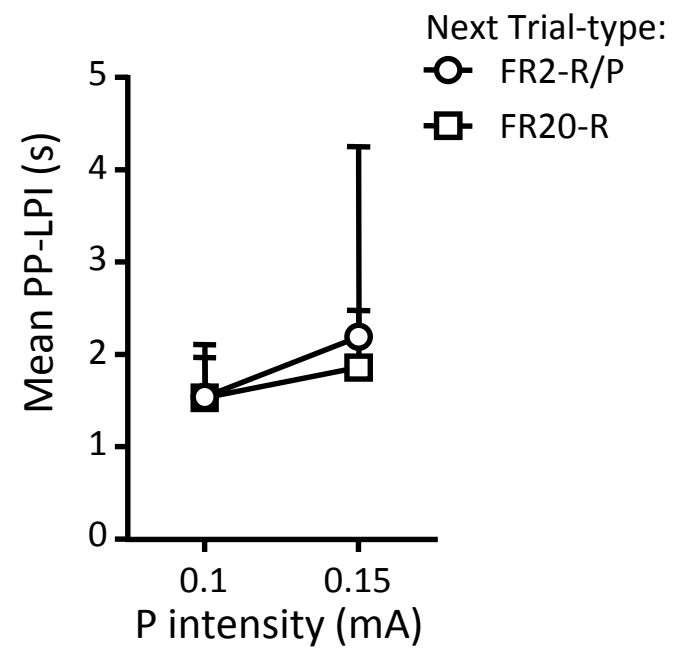


Figure 6
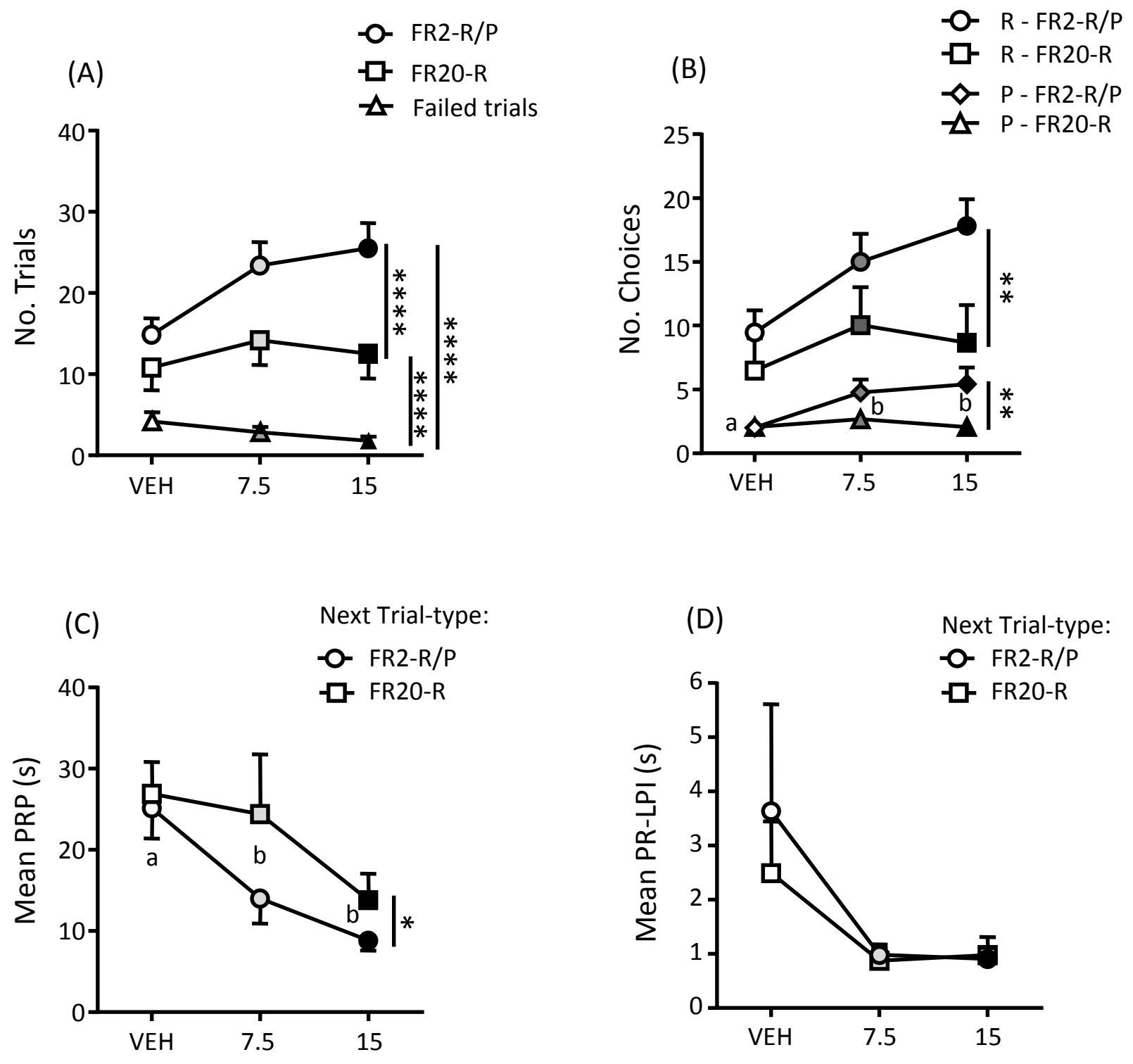

(E)

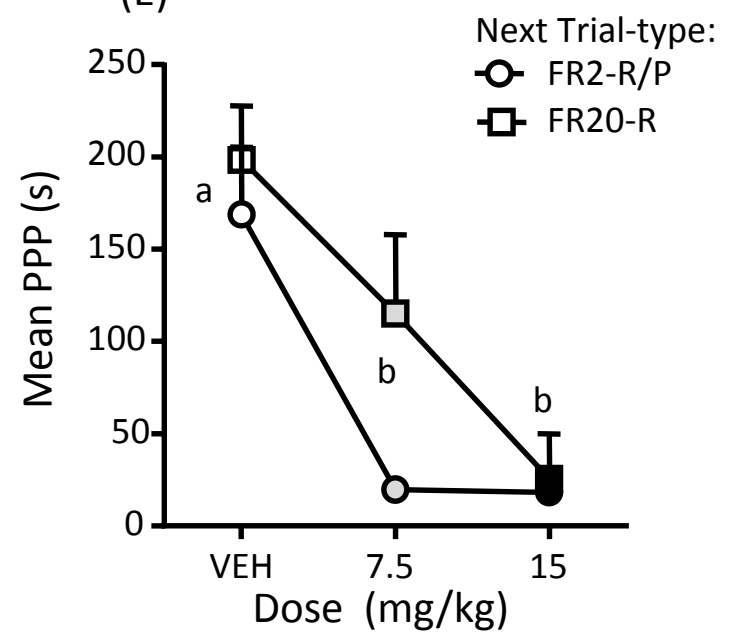

(F)

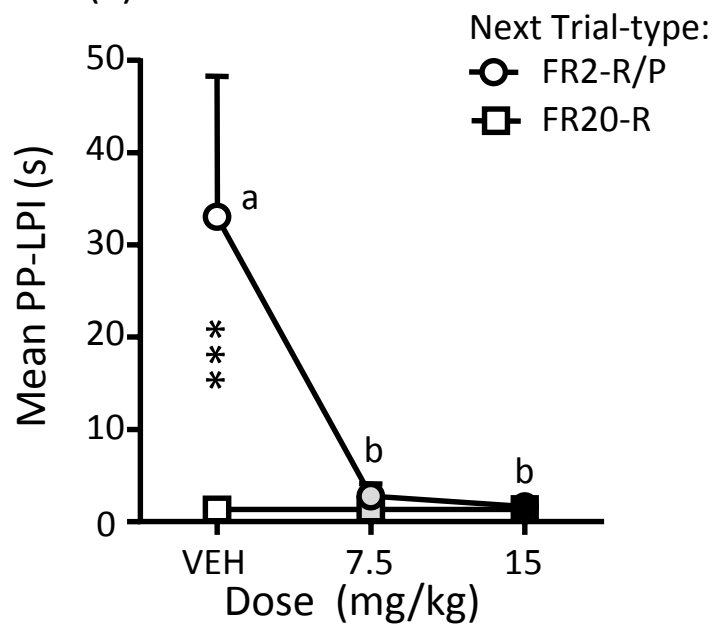


Table 1. Parameter effects in the 1LOC and 2LOC tests (see figures for further details)

\section{One lever operant conflict test}

R1 phase, Dose LMM

\begin{tabular}{lll} 
& $\operatorname{PRP}(s)$ & $\mathrm{LPI}(\mathrm{s})$ \\
\hline Dose & $\mathrm{F}(2,30)=8.45, p<0.002$ & $F(2,30)=4.43, p<0.02$
\end{tabular}

R+P phase, Trial type $\times$ Dose LMM (see Fig. 4C, 4D)

Pause (PRP, PPP) LPI

$\begin{array}{lll}\text { Trial type } & F(1,85)=14.45, p<0.0001 & F(1,85)=11.40, p<0.01 \\ \text { Dose } & F(2,85)=27.14, p<0.0001 & F(2,85)=4.6, p<0.02 \\ \text { Trial type } x \text { Dose } & F(2,85)=5.15, p<0.008 & F(2,85)=3.26, p<0.05\end{array}$

\section{Two lever operant conflict test}

Footshock amplitude $x$ Lever choice LMM (see Fig. 5B, 5C, 5D, 5E)

\begin{tabular}{lllll} 
& PRP & PR-LPI & PPP & PP-LPI \\
\hline Footshock amplitude & $\begin{array}{l}F(2,82)=9.42 \\
p<0.0001\end{array}$ & $\begin{array}{l}F(2,84)=16.89 \\
p<0.0001\end{array}$ & $\begin{array}{l}F(1,43)=9.20 \\
p<0.004\end{array}$ & $\begin{array}{l}F(1,46)=0.76 \\
p=0.4\end{array}$ \\
& $\begin{array}{l}F(1,82)=7.26 \\
\text { Lever choice }\end{array}$ & $\begin{array}{l}F(1,84)=0.26 \\
p=0.009\end{array}$ & $\begin{array}{l}F(1,42)=4.23 \\
p<0.05\end{array}$ & $\begin{array}{l}F(1,48)=0.29 \\
p=0.6\end{array}$ \\
$\begin{array}{l}\text { Footshock amplitude } \\
\text { X Lever choice }\end{array}$ & $\begin{array}{l}F(2,82)=2.55 \\
p=0.08\end{array}$ & $\begin{array}{l}F(2,84)=1.28 \\
p=0.3\end{array}$ & $\begin{array}{l}F(1,43)=0.84 \\
p=0.4\end{array}$ & $\begin{array}{l}F(1,46)=0.27 \\
p=0.6\end{array}$
\end{tabular}

CDZ dose $x$ Lever choice LMMs (see Fig. 6B)

\begin{tabular}{|c|c|c|}
\hline & PR choice & PP choice \\
\hline CDZ dose & $\begin{array}{l}F(2,84)=2.49 \\
p=0.09\end{array}$ & $\begin{array}{l}F(2,84)=3.06 \\
p=0.05\end{array}$ \\
\hline Lever choice & $\begin{array}{l}F(1,84)=7.48 \\
p<0.008\end{array}$ & $\begin{array}{l}F(1,84)=8.08 \\
p<0.006\end{array}$ \\
\hline $\begin{array}{l}\text { CDZ dose } \\
\text { X Lever choice }\end{array}$ & $\begin{array}{l}F(2,84)=0.71 \\
p=0.49\end{array}$ & $\begin{array}{l}F(2,84)=2.51 \\
p=0.09\end{array}$ \\
\hline
\end{tabular}


CDZ dose $x$ Lever choice LMMs (see Fig. 6C, 6D, 6E, 6F)

\begin{tabular}{lllll} 
& PRP & PR-LPI & PPP & PP-LPI \\
\hline CDZ dose & & & & \\
& $\begin{array}{l}F(2,60)=10.05 \\
p<0.0001\end{array}$ & $\begin{array}{l}F(2,66)=2.76 \\
p=0.07\end{array}$ & $\begin{array}{l}F(2,60)=9.61 \\
p<0.0001\end{array}$ & $\begin{array}{l}F(2,47)=3.83 \\
p<0.03\end{array}$ \\
Lever choice & $\begin{array}{l}F(1,62)=5.18 \\
p<0.03\end{array}$ & $\begin{array}{l}F(1,67)=0.18 \\
p=0.7\end{array}$ & $\begin{array}{l}F(1,65)=2.63 \\
p=0.1\end{array}$ & $\begin{array}{l}F(1,57)=4.52 \\
p<0.04\end{array}$ \\
& & & & \\
CDZ dose & $F(2,60)=0.74$ & $F(2,66)=0.26$ & $F(2,59)=0.50$ & $F(2,46)=3.91$ \\
$X$ Lever choice & $p=0.5$ & $p=0.6$ & $p=0.8$ & $p<0.03$ \\
\hline
\end{tabular}


Table 2. Summary of findings for effects of previous-trial reward versus punishment and of chlordiazepoxide versus vehicle on response latency, vigour and choice

\begin{tabular}{|c|c|c|c|c|}
\hline & \multicolumn{2}{|c|}{ One-Lever Operant Conflict Test } & \multicolumn{2}{|c|}{ Two-Lever Operant Conflict Test } \\
\hline & $\begin{array}{l}\text { Post-Reward vs. } \\
\text { Post-Punishment } \\
\text { (VEH sessions) }\end{array}$ & $\begin{array}{l}\text { CDZ vs. VEH } \\
\text { (CDZ at } 7.5 \\
\text { and/or } 15 \mathrm{mg} / \mathrm{kg} \text { ) }\end{array}$ & $\begin{array}{l}\text { Post-Reward vs. } \\
\text { Post-Punishment } \\
\text { According to next Trial-type } \\
\text { (VEH sessions) }\end{array}$ & $\begin{array}{l}\text { CDZ vs. VEH } \\
\text { (CDZ at } 7.5 \\
\text { and/or } 15 \mathrm{mg} / \mathrm{kg} \text { ) } \\
\text { According to previous and next Trial-type }\end{array}$ \\
\hline \multirow[t]{2}{*}{ Response Latency } & $P P>P R$ & PR: CDZ < VEH & FR2: PP > PR & PR: FR2: CDZ < VEH; FR20: CDZ < VEH \\
\hline & & PP: CDZ < VEH & FR20: PP > PR & PP: FR2: CDZ < VEH; FR20: CDZ < VEH \\
\hline \multirow[t]{2}{*}{ Response Vigour } & $\mathrm{PR}>\mathrm{PP}$ & PR: CDZ = VEH & FR2: $P P<P R$ & PR: FR2: CDZ = VEH; FR20: CDZ = VEH \\
\hline & & PP: CDZ > VEH & FR20: $P P=P R$ & PP: FR2: CDZ > VEH; FR20: CDZ = VEH \\
\hline \multirow[t]{2}{*}{ Response Choice } & & & PR: FR2 = FR20 & PR Total choices: CDZ = VEH \\
\hline & & & PP: FR2 = FR20 & PP Total choices: $C D Z>$ VEH \\
\hline
\end{tabular}

Response latency: Pause to first operant response after time out. Respone vigour: Inverse of the mean interval between consecutive operant responses. Response choice:

Number of trials completed on a particular lever within a session.

PP: post-punishment trials. PR: post-reward trials.

FR2: Operant lever at which 2 responses yielded sucrose at $p=0.7$ and footshock at $p=0.3$ on average. FR20: Operant lever at which 20 responses yielded sucrose at $p=1$

$>,<p<0.05 ; \leq p<0.10 ;=p>0.10$. 